\title{
Applying fuzzy proportional integral derivative on Internet of things for figs greenhouse
}

\author{
Andi Riansyah, Sri Mulyono, M. Roichani
}

Teknik Informatika, Universitas Islam Sultan Agung, Indonesia

\begin{tabular}{l} 
Article Info \\
\hline Article history: \\
Received Mar 5, 2020 \\
Revised May 5, 2021 \\
Accepted May 20, 2021 \\
\hline
\end{tabular}

\section{Keywords:}

Figs

Fuzzy Tsukamoto

Greenhouse

Internet of things

Proportional integral derivative

\begin{abstract}
Indonesia is an agrarian country where most of population work as farmers. Various planting media have been developed in Indonesia such as using greenhouses. Greenhouse is one of very promising planting media for plant cultivators, because it can be a solution to challenges of extreme climate change. In a greenhouse, the state of the room can be easily controlled using technologies such as automatic watering systems, air temperature control, air humidity and soil moisture. This research focuses on figs by applying fuzzy proportional integral derivative (FPID) as artificial intelligence on the Internet of things (IoT) for greenhouses. It uses Tsukamoto method serves to monitor air conditions and soil conditions and then it is coupled with proportional integral derivative (PID) control to control air temperature, air humidity, and soil moisture so that it is always in the ideal condition of figs in greenhouse. By implementing FPID on IoT for greenhouse, the development of figs in greenhouse can be optimized because air and soil conditions can be maintained in ideal conditions.
\end{abstract}

This is an open access article under the CC BY-SA license.

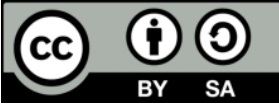

\section{Corresponding Author:}

Andi Riansyah

Teknik Informatika

Universitas Islam Sultan Agung

Jl. Raya Kaligawe Km.4 Semarang 50112, Jawa Tengah

Email: andi@unissula.ac.id

\section{INTRODUCTION}

Indonesia is an agrarian country where most of the population living as farmers. Fertile nature, vast expanses of land and a tropical climate are very supportive of farming without any restrictions. But lately productivity in the agricultural sector is very lacking, due to changes in extreme climatic conditions that cause plants cannot grow optimally. While optimizing productivity in the agricultural sector will provide extraordinary benefits, both to support food, food sovereignty, public welfare, and create a country that can produce the largest food output in the world, the agricultural sector is one of the largest in maintaining the national economy.

One of the efforts undertaken by the community to strengthen the economy at this time is to move to cultivate some rare fruits and have promising business value such as figs. Figs village in the Semarang area was developed in the village of Karang Tempel, East Semarang, where figs plants have been developed since about 4-5 years ago. Figs is a fruit that contains carbohydrates, protein, and oil. Apart from being a food supply, figs can also be used for health because they contain alkaline substances that the body needs. The active substance inside resembles a cleanser that can be used to treat external wounds [1].

In order to increase the productivity of figs, various planting media have been developed in Indonesia such as the use of greenhouses in the treatment of figs have things to consider such as water needs, sunlight, temperature, and humidity, because figs are not native plants of Indonesia. Problems that arise are 
the irrigation of plants which sometimes gets less attention, and the temperature is uncertain, because the treatment of figs in the greenhouse is still controlled conventionally, of course it all affects the plant growth.

Based on the description above, this research will create a control and monitoring system by applying fuzzy proportional integral derivative (FPID) as artificial intelligence on Internet of things (IoT) for figs plants in greenhouses [2]-[4]. Using of the fuzzy Tsukamoto method serves to monitor air conditions and soil conditions and then coupled with proportional integral derivative (PID) control to control air temperature, air humidity, and soil moisture so that it is always in the ideal condition of figs in greenhouse. By implementing FPID on IoT for greenhouse, the development of figs in greenhouse can be optimized because air and soil conditions can be maintained in ideal conditions.

\section{RESEARCH METHOD}

\subsection{Internet of things}

IoT is a very promising technological development to optimize life based on smart sensors and smart equipment that works together through the internet network [5], [6]. Using computers in the future is able to dominate human work and defeat human computing capabilities such as controlling electronic equipment remotely using internet media, IoT allows users to manage and optimize electronics and electrical equipment that uses the internet. We can utilize the IoT system for monitoring and control of the greenhouse environment [5], [7]-[10]. This speculates that in the near future communication between computers and electronic equipment is able to exchange information between them thereby reducing human interaction. This will also increase the number of internet users with various internet facilities and services [6], [11]. Design of IoT system on greenhouse shown in Figure 1.

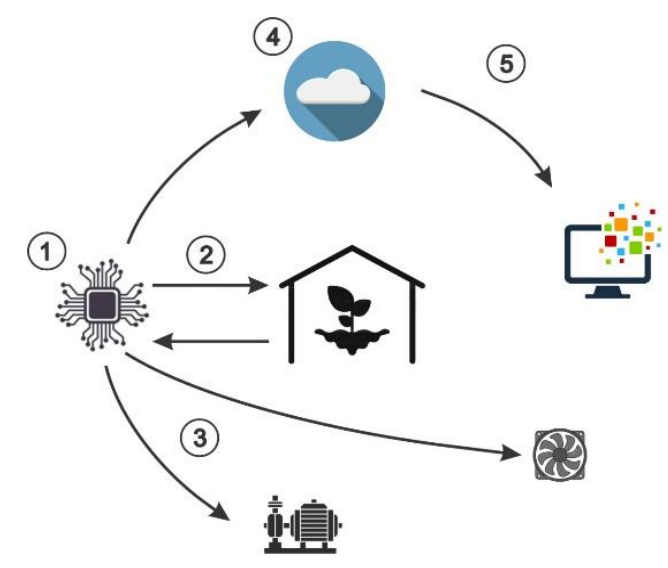

Figure 1. Design of IoT system on greenhouse

Description:

- Microcontroller has input and output, for input using DHT11 sensor and soil moisture sensor, both sensors are in greenhouse.

- From two sensors get data which is then sent to the microcontroller to be processed.

- After data is processed, data becomes the value of the output status determinant, the first output in the water pump to meet water needs and the second output is an air controller that serves to neutralize temperature and humidity of greenhouse.

- Data that has been processed in the microcontroller is also sent to the adafruit.io server in order to monitor the state of air temperature, humidity, and soil conditions in greenhouse.

- After sending to adafruit.io server, the server will display data on users using the website.

\subsection{Cloud computing}

A simple understanding of cloud computing is computing happens on the internet. The internet is generally visualized as cloud, so the term "cloud computing" for computing is processed through the Internet. Users can access database resources via internet from anywhere, as long as they need. In addition, databases in the cloud are very dynamic and can be scaled. cloud systems to enable data-based services and overcome the challenges of complexity and resource demands for online, offline data processing, storage, and analysis [10]-[13]. The best example of cloud computing is Google Apps where any application can be accessed 
using a browser and can be used on thousands of computers via internet [14]. Concept of cloud computing shown in Figure 2.

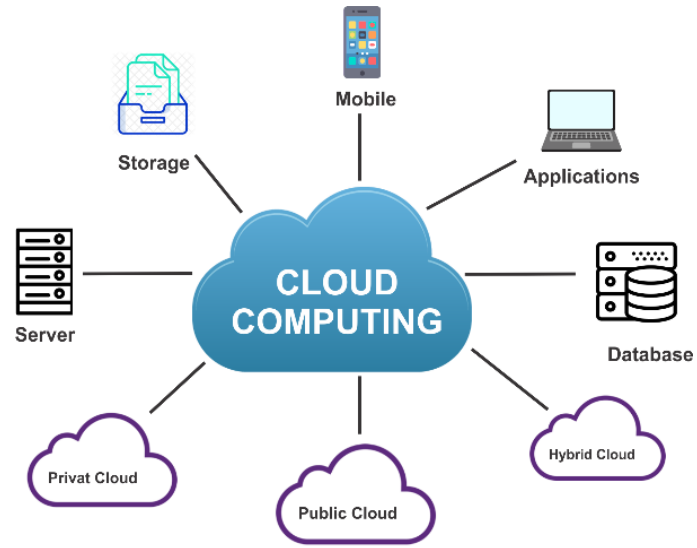

Figure 2. Concept of cloud computing

\subsection{MQTT protocol}

The message queuing telemetry transport (MQTT) protocol is a simple, lightweight publish/subscribe communication protocol designed for devices with limited capabilities. MQTT has the ability to be able to support an IoT device. MQTT in principle has an information exchange center between subscriber and publisher namely MQTT broker. Publisher is sending data such as sensors while the subscriber is sending data such as humans [6], [12]. Concept of MQTT shown in Figure 3.

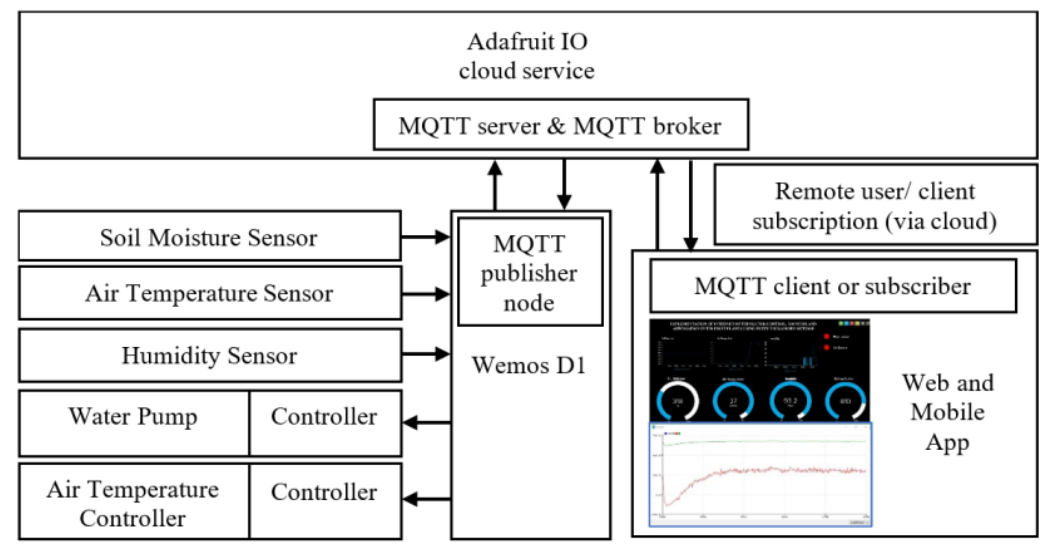

Figure 3. MQTT concept

There are MQTT Clients and MQTT brokers or can also be called MQTT servers. When the MQTT client wants to broadcast or publish some information to the MQTT broker, the client needs to make a connection with the MQTT broker. The client asks the broker to connect, then the broker sends a connection request notification to the client after a connection is made between the client and the MQTT broker. Clients can send or publish information to brokers [15], [16]. The MQTT protocol is divided into several features namely:

a. Publish and subscribe provide one to many messaging.

b. Has three levels of qualities of service (QoS): "At most once", messages will be sent using the best TCP/IP network. Message missing or duplication is likely to occur "at least once", the message will be delivered even though duplication can occur. "Exactly once", the message can arrive exactly once.

c. Uses TCP/IP connections for basic connections.

\subsection{Fuzzy Tsukamoto}


Fuzzy logic is a branch of computer science that studies the value of truth that has a lot of value [6], [17]. It is different from the truth value in classical logic which is 0 (false) or 1 (true). Fuzzy logic has a real truth value in the interval [0,1]. Fuzzy logic was first developed by Lotfi A. Zadeh, an Iranian American scientist from the University of California at Berkeley. However, fuzzy logic was more developed by Japanese practitioners. Design of triangle curve shown in Figure 4.

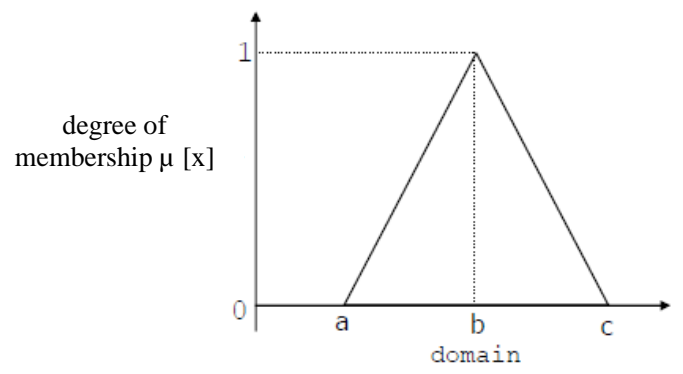

Figure 4. Triangle curve

$$
\mu[\mathrm{x}]=\left\{\begin{array}{cc}
0 ; & x \leq \text { a atau } x \geq c \\
(x-a) /(b-a) & a \leq x \leq b \\
(c-x) /(c-b) ; & b \leq x \leq c
\end{array}\right.
$$

In the fuzzy Tsukamoto method, each consequence of IF-THEN rules must be presented with a fuzzy set with a monotonous membership function. Tsukamoto's fuzzy logic was chosen because it gives an output of sharp individual rules [18]-[20]. As a result, the output of the inference results from each rule is given explicitly (crisp) based on $\alpha$-predicate (fire strength), then the final result is obtained using a weighted average. Stages of how fuzzy Tsukamoto works:

a. Fuzzification

The process of converting system inputs that have explicit values into linguistic variables uses membership functions stored in the knowledge base.

b. Formation of a fuzzy knowledge base (Rule in the form of IF-THEN).

c. Inference engine

Process of converting fuzzy input into fuzzy output by following the rules (IF-THEN Rules) that have been set on fuzzy knowledge.

d. Aggregation

There are often cases where there is more than one rule. This means that the results of the implication are worth more than one. Therefore, we need to combine all the results of these results into one single fuzzy set. The aggregation method used here is the MIN method.

e. Defuzzification

Process for converting fuzzy output obtained from an inference engine into an explicit value using the membership function that is in accordance with when Fuzzification was performed. With calculations:

- Weighted average method.

$$
Z^{*=\frac{\int \mu(z) \cdot z d z}{\int \mu(z) d z}}
$$

- $\quad$ Center of area method

$$
z^{*=\frac{\sum \alpha_{i} * z_{i}}{\sum \alpha_{i}}}
$$

\subsection{Proportional integral derivative control}

Proportional integral derivative (PID) control is a control system that has long been used in industry or the military. $90 \%$ of industrial equipment already uses PID control because it is easy and simple to use. The use of this PID aims to stabilize the output speed in the form of a water pump and air controller [4], [21]-[24]. The advantages of using PID controls are:

- If using a relay can only control Output with active and inactive status only. 
- However, if using PID control, the status control is not active and no longer active, but with a slow, normal, and fast status.

Using the PID control can be used separately or together and not use any of the P, I or D components [25], [26] shown in Figure 5.

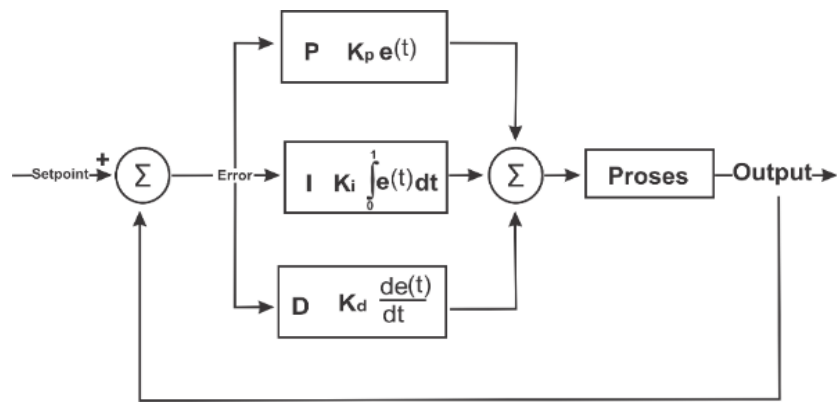

Figure 5. PID control diagram

PID control is the combined result of three forms of control, namely Proportional, Integral and Derivative control

$$
u_{P I D}=K_{p} e(t)+K_{i} \int_{0}^{t} e(t) d t+K_{d} \frac{d e}{d t}
$$

Description:

$\mathrm{u}(\mathrm{t})=$ control signal

$\mathrm{K}=$ strengthening

$\mathrm{e}(\mathrm{t})=$ error signal obtained from the difference between the Output signal value minus setpoint signal.

$\mathrm{Kp}=$ Proportional parameters

$\mathrm{Ki}=$ Integral parameters

$\mathrm{Kd}=$ Derivative parameters

The main parameters of the PID controller are proportional strengthening of $\mathrm{Kp}$, integral time $\mathrm{Ti}$, and derivative time $\mathrm{Td}$. The equation is an equation in time value $(\mathrm{t})$, so that equation is converted by using a first-order differential finite. The detailed explanation of PID is:

- Proportional control

Proportional control has an output that is proportional to the error signal (the difference between the intended value and actual value, error). Changes in input will affect output by its multiplying constant. The proportional control equation is formulated as:

$$
u(t)=K_{p} e(t)
$$

Description:

$\mathrm{Kp}=$ Proportional parameters

$e=$ error

$u=$ is an output of values relative to time $(t)$

- Integral control

Integral control has a function to eliminate the steady-state error to zero. If a plan does not have an integrator element $(1 / \mathrm{s})$, the proportional controller cannot be able to guarantee that system output will be exactly according to desired response, so an integral controller is needed. The integral control equation is formulated as:

$$
u(t)=K_{i} \int_{0}^{t} e(t) d t
$$

Description:

$\mathrm{Ki}=$ Integral parameters

$e=$ error

$u=$ is an output of values relative to time $(t)$ 
- Derivative control

Output value of derivative is differential, derivative control using speed of error signal changes as a control parameter. If there is no change in error signal, output of derivative control will not change. The derivative control equation is formulated as:

$$
u(t)=K_{d} \frac{d}{d t} e(t)
$$

Description:

$K d=$ Proportional parameters

$e=$ error

$u=$ is an output of values relative to time $(t)$

\section{RESULTS AND ANALYSIS}

Implementation is the stage carried out to implement a system that has been built in accordance with the system design. The following is an interface display of the IoT system on the greenhouse that has been developed based on the web shown in Figure 6.

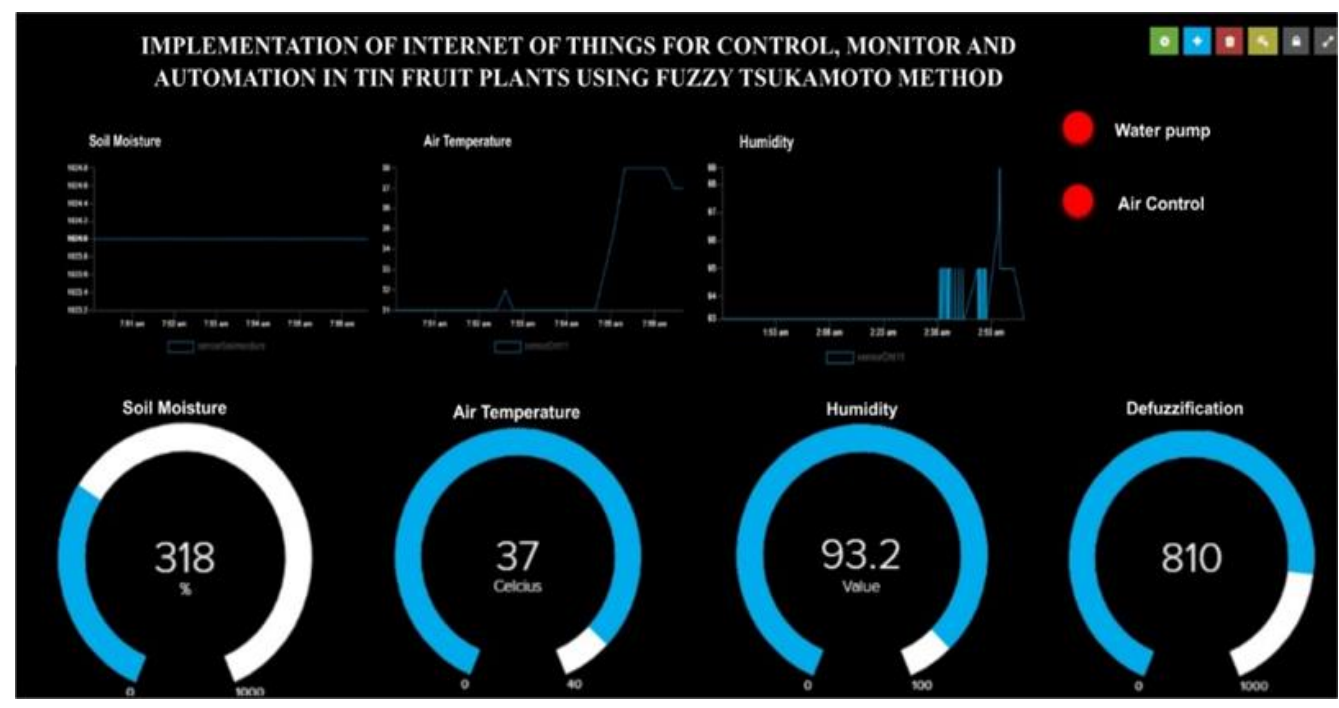

Figure 6. IoT data monitor dashboard on the greenhouse

Information displayed by the Adafruit IO dashboard to monitor data from IoT in the greenhouse. Data displayed in system are soil moisture, air temperature, humidity, water pump status, air controller status, and defuzzification value from calculation results that have been made. The value of humidity and air temperature obtained from DHT11 sensor and soil moisture values obtained from soil moisture sensor. Three input variables will be input from the fuzzy process. To get the defuzzification value of three variables will be processed on the rule base and inference engine. As a result of defuzzification of the pump into a setpoint value for PID control, PID control is used to control the speed of the water pump and the air controller to keep it stable so that the speed suddenly increases or decreases dramatically, as a pump speed test without using PID and using PID is shown in Figures 7 and 8.

In Figure 7 the pump speed that does not use PID control so that to adjust pump speed it still looks rough in an increasing and decreasing position. Very different if you use a PID control as shown in Figure 8. In Figure 8 is the pump speed using PID control. PID tuning using a trial-error method with the simulation conditions used values of $\mathrm{Kp}=2, \mathrm{Kd}=0.03, \mathrm{Ki}=0.2$ with $\mathrm{t}=0.10 \mathrm{~s}$ and the setpoint of the results of defuzzification will produce 370 that are close to the setpoint number. 


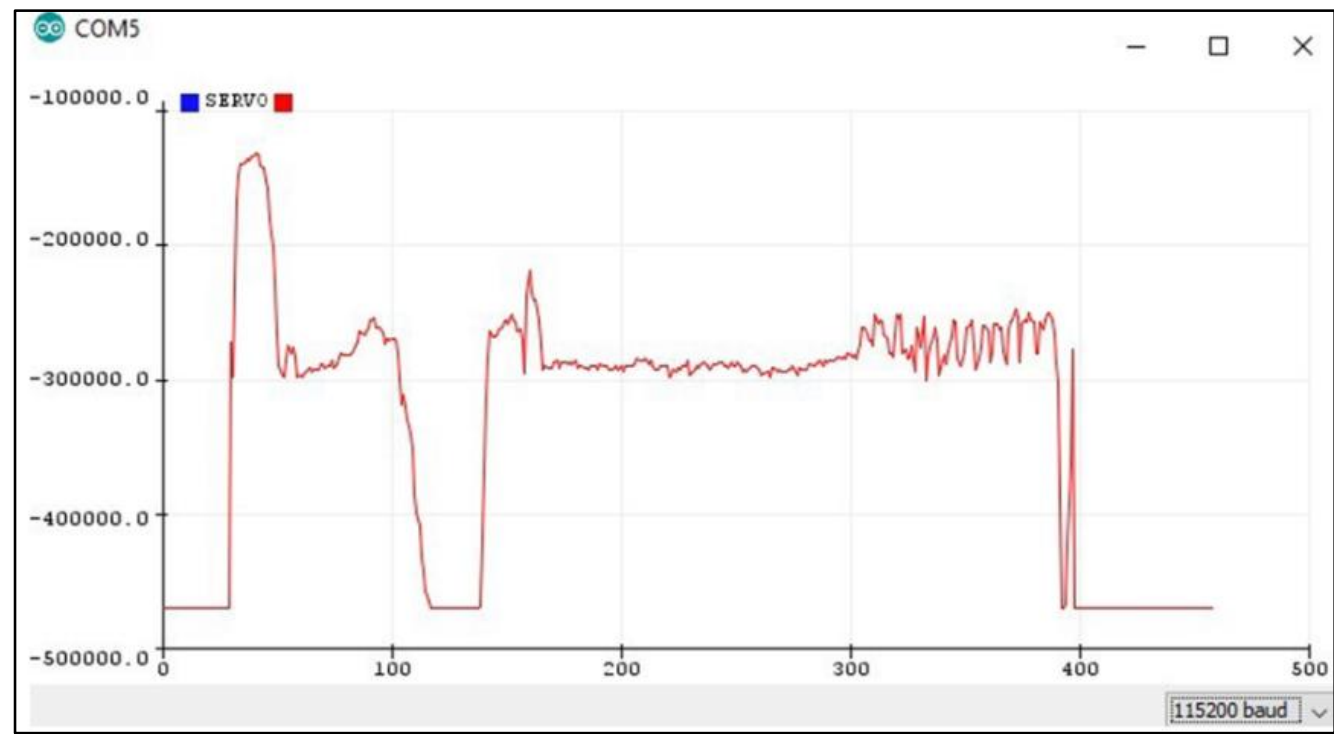

Figure 7. Without using PID control

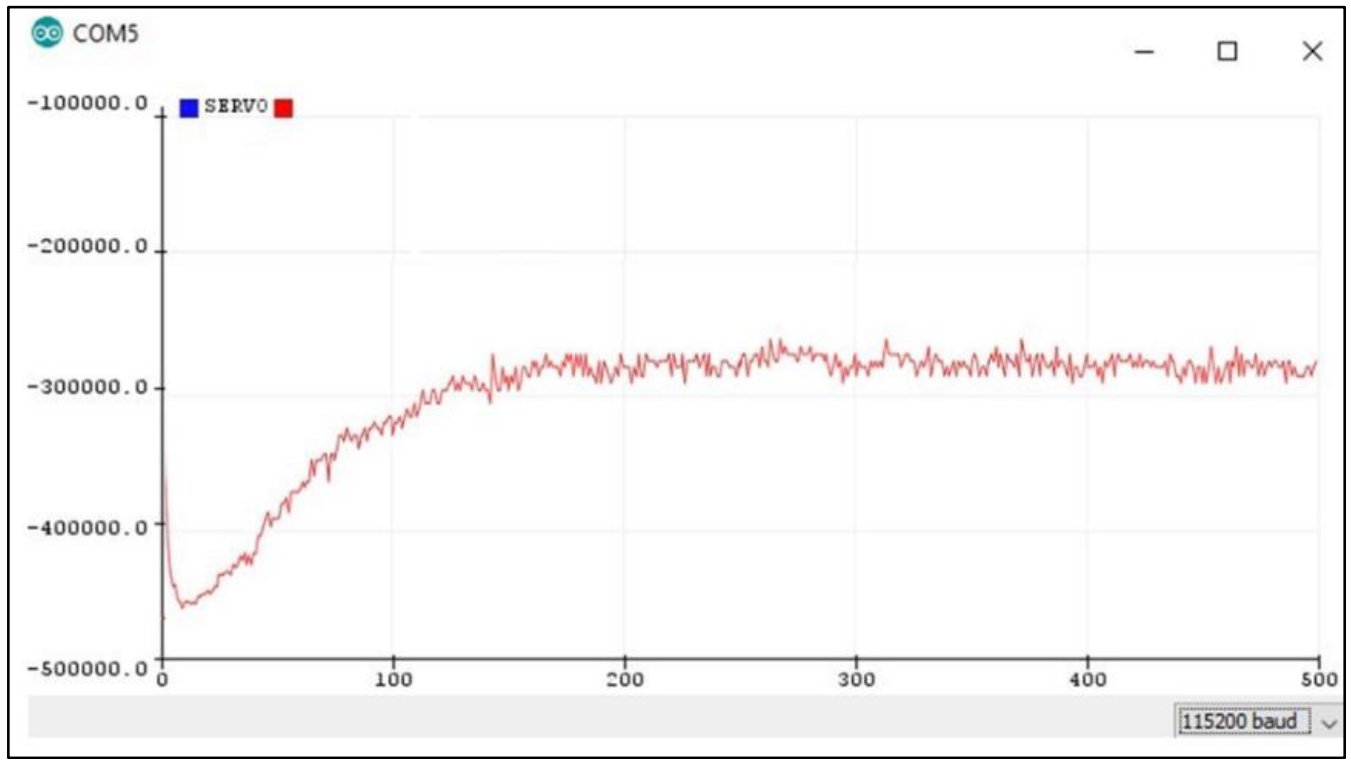

Figure 8. Using PID control

For calculations in the program is:

$$
\begin{aligned}
& \text { Error }=\text { setpoint }- \text { input } \\
& \text { Errorl }=\text { Error }+ \text { Error_previous } \\
& \text { Error } 2=\text { Error }- \text { Error } r_{-} \text {previous } \\
& \mathrm{P}=\mathrm{KP} \times \text { Error } \\
& \mathrm{I}=\mathrm{KI} \times \text { Errorl } \\
& \mathrm{D}=\mathrm{KD} \times \text { Error } 2 \\
& \text { Error }- \text { previous }=\text { Error } \\
& \mathrm{PID}=\mathrm{P}+\mathrm{I}+\mathrm{D}
\end{aligned}
$$

From the real-time data the PID calculation gets the results shown in Table 1. The table shows the data from the control PID calculation with values of $\mathrm{Kp}=1.0, \mathrm{Ki}=0.5$, and $\mathrm{Kd}=0.2$ with $\mathrm{t}$ (time) $=0.100 / \mathrm{s}$ and the setpoint of the defuzzification results. 
Table 1. Results of PID control calculations

\begin{tabular}{ccccccc}
\hline No & Time & P & I & D & Error & Output \\
\hline 1 & $15: 51: 51.477$ & 111.00 & 95.00 & 6.40 & 111.00 & 212 \\
2 & $15: 51: 51.579$ & 159.00 & 135.00 & 9.60 & 159.00 & 303 \\
3 & $15: 51: 51.579$ & 155.00 & 157.00 & -0.80 & 155.00 & 311 \\
4 & $15: 51: 52.762$ & 227.00 & 195.00 & 12.80 & 227.00 & 434 \\
\hline
\end{tabular}

\section{CONCLUSION}

The system developed to implement FPID on IoT installed in greenhouse has run according to expectations. With the presence of IoT air and soil conditions can be monitored in real-time, process of watering also runs according to needs of the figs with real-time. By applying FPID as artificial intelligence to IoT installed in a greenhouse, the development of figs in the greenhouse can be optimal because air and soil conditions can be maintained in ideal conditions.

\section{ACKNOWLEDGEMENTS}

We thank the DSIS Science and Data Systems Research Group, Informatics Department of Sultan Agung Islamic University for their research support. Thank you also to all researchers who are members of the research group.

\section{REFERENCES}

[1] S. L. Keoh, S. S. Kumar, and H. Tschofenig, "Securing the Internet of Things: A Standardization Perspective," IEEE Internet of Things Journal, vol. 1, no. 3, pp. 265-275, 2014, doi: 10.1109/JIOT.2014.2323395.

[2] D. Li et al., "Fuzzy-PID controller for motion control of CFETR Multi-Functional Maintenance Platform," Nuclear Engineering and Technology, February 2021, doi: 10.1016/j.net.2021.01.025.

[3] Y. Feng, M. Wu, X. Chen, L. Chen, and S. Du, "A fuzzy PID controller with nonlinear compensation term for mold level of continuous casting process," Information Sciences, vol. 539, pp. 487-503, 2020, doi: 10.1016/j.ins.2020.06.024.

[4] H. Hazfiza, A. Khairi, A. Wahab, and F. Mohamed, "Biomedical Signal Processing and Control for Carbon Dioxide Exchange Process in a Membrane Oxygenator Using Online Self-Tuning Fuzzy-PID Controller," Biomedical Signal Processing and Control, vol. 64, no. October 2020, p. 102300, 2021, doi: 10.1016/j.bspc.2020.102300.

[5] D. Karimanzira and T. Rauschenbach, "Enhancing aquaponics management with IoT-based Predictive Analytics for efficient information utilization," Information Processing in Agriculture, vol. 6, no. 3, pp. 375-385, 2019, doi: 10.1016/j.inpa.2018.12.003.

[6] A. Riansyah, D. Kurniadi, and Saebani, "Fuzzy Tsukamoto Implementation on Internet of Things to Control Flooding," TRANSFORMATIKA, vol.17, No.2, pp. 171-176, 2020, doi:10.26623/transformatika.v17i2.1700.

[7] J. Wang, M. Chen, J. Zhou, and P. Li, "Data communication mechanism for greenhouse environment monitoring and control: An agent-based IoT system," Information Processing in Agriculture, vol. 7, no. 3, pp. 444-455, 2019, doi: 10.1016/j.inpa.2019.11.002.

[8] M. Liao et al., "On precisely relating the growth of Phalaenopsis leaves to greenhouse environmental factors by using an IoT-based monitoring system," Computers and Electronics in Agriculture, vol. 136, pp. 125-139, 2017, doi: 10.1016/j.compag.2017.03.003.

[9] A. Khanna and S. Kaur, "Evolution of Internet of Things (IoT) and its significant impact in the field of Precision Agriculture," Computers and Electronics in Agriculture, vol. 157, pp. 218-231, 2019, doi: 10.1016/j.compag.2018.12.039.

[10] M. Wang and Q. Zhang, "Optimized data storage algorithm of IoT based on cloud computing in distributed system," Computer Communications, vol. 157, no. April, pp. 124-131, 2020, doi: 10.1016/j.comcom.2020.04.023.

[11] G. Wu, W. Ma, C. Liu, and S. Wang, "IOT and cloud computing based parallel implementation of optimized RBF neural network for loader automatic shift control," Computer Communications, vol. 158, no. April, pp. 95-103, 2020, doi: 10.1016/j.comcom.2020.04.053.

[12] L. Zhou, X. Li, K. H. Yeh, C. Su, and W. Chiu., "Lightweight IoT-based authentication scheme in cloud computing Circumstance," Future Generation Computer Systems, vol. 91, pp. 244-251, 2019, doi: 10.1016/j.future.2018.08.038.

[13] A. Yassine, S. Singh, M. Shamim Hossain, and G. Muhammad, "IoT big data analytics for smart homes with fog and cloud computing," Future Generation Computer Systems, vol. 91, pp. 563-573. 2019, doi: 10.1016/j.future.2018.08.040.

[14] W. Liao and P. Chen, "A Resource Provision Strategy for Software-as-a-Service in Cloud Computing," Procedia Computer Science, vol. 110, pp. 94-101, 2017, doi: 10.1016/j.procs.2017.06.123.

[15] M. Kashyap, V. Sharma, and N. Gupta, "Taking MQTT and NodeMCU to IOT: Communication in Internet of Things," in International Conference on Computational Intelligence and Data Science (ICCIDS 2018), pp. 16111618, 132, 2018, doi: 10.1016/j.procs.2018.05.126. 
[16] C. A. Garcia, W. Montalvo-Lopez, and M. V. Garcia, "Human-robot collaboration based on cyber-physical production system and MQTT," Procedia Manufacturing, vol. 42, pp. 315-321, 2020, doi: 10.1016/j.ins.2020.06.024.

[17] M. Haddin, A. Marwanto, M. Ismail, A. Riansyah, and F. A. Cholid, "Data Acquisition in Determining Lab Work Assesment Ranking Using Fuzzy Analytic Hierarchy Process (FAHP)," in International Seminar on Application for Technology of Information and Communication (iSemantic), pp. 346-353, Sept. 21-22, 2019, doi: 10.1109/ISEMANTIC.2019.8884220.

[18] S. Suharjito, D. Diana, Y. Yulyanto, and A. Nugroho, "Mobile Expert System Using Fuzzy Tsukamoto for Diagnosing Cattle Disease", in 2nd International Conference on Computer Science and Computational Intelligence 2017, vol. 116, pp. 27-36, Oct. 13-14, 2017, doi: 10.1016/j.procs.2017.10.005.

[19] F. J. Atletiko, N. A. Rakhmawati, and H. A. Ts, "Determination of Freight Rates Based on Package Dimension and Distance of Delivery Using Fuzzy Logic System Dimension in Angkotin Determination of Freight Rates Based on Package and Application Distance of Deliver," Procedia Computer Science, vol. 161, pp. 527-534, 2019, doi: 10.1016/j.procs.2019.11.152.

[20] P. K. Gupta and P. K. Muhuri, "Extended Tsukamoto's inference method for solving multi-objective linguistic optimization problems," Fuzzy Sets and Systems, vol. 1, pp. 1-23, 2019, doi: 10.1016/j.fss.2019.02.022.

[21] E. Y. Bejarbaneh, A. Bagheri, B. Y. Bejarbaneh, S. Buyamin, and S. N. Chegini, "A new adjusting technique for PID type fuzzy logic controller using PSOSCALF optimization algorithm," Applied Soft Computing Journal, vol. 85, p. 105822 , 2019, doi: 10.1016/j.asoc.2019.105822.

[22] G. L. Grandi and J. O. Trierweiler, "Tuning of fractional order PID controllers based on the frequency response approximation method," IFAC-PapersOnLine, vol. 52, no. 1, pp. 982-987, 2019, doi: 10.1016/j.ifacol.2019.06.190.

[23] Z. Wu, D. Li, Y. Xue, T. He, and S. Zheng, "Tuning for Fractional Order PID Controller based on Probabilistic Robustness," IFAC-PapersOnLine, vol. 51, no. 4, pp. 675-680, 2018, doi: 10.1016/j.ifacol.2017.08.2093

[24] N. P. Lawrence, G. E. Stewart, P. D. Loewen, M. G. Forbes, J. U. Backstrom, and R. B. Gopaluni, "Optimal PID and antiwindup control design as a reinforcement learning problem," arXiv, vol. 53, no. 2, pp. 236-241, 2020, doi: 10.1016/j.ifacol.2020.12.129.

[25] Q. Shi, H. K. Lam, C. Xuan, and M. Chen, "Adaptive neuro-fuzzy PID controller based on twin delayed deep deterministic policy gradient algorithm," Neurocomputing, vol. 402, pp. 183-194, 2020, doi: 10.1016/j.neucom.2020.03.063.

[26] S. K. Valluru, R. Kumar, and R. Kumar, "Design and Real Time implementation of fmincon, MOGA tuned IO-PID and FO-PI $\lambda \mathrm{D} \mu$ Controllers for Stabilization of TRMS," Procedia Computer Science, vol. 171, no. 2019, pp. 12411250, 2020, doi: 10.1016/j.procs.2020.04.305. 